\title{
BEHAR, Patrícia Alejandra (Org.). Competências em Educação a Distância. Porto Alegre: Penso, 2013.
}

RESENHA

Giselle Massaro ${ }^{\mathrm{a}}$

\section{Editor}

Maria Inês Côrte Vitoria PUCRS, RS, Brasil

\section{Equipe Editorial}

Pricila Kohls dos Santos PUCRS, RS, Brasil

Marcelo Oliveira da Silva PUCRS, RS, Brasil

Carla Spagnolo PUCRS, RS, Brasil Rosa Maria Rigo PUCRS, RS, Brasil

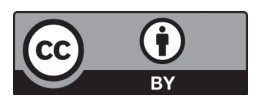

A matéria publicada neste periódico é licenciada sob forma de uma Licença Creative Commons - Atribuição 4.0 Internacional. http://creativecommons.org/licenses/by/4.0/
$\mathrm{O}$ livro resenhado foi organizado por Patrícia Alejandra Behar, Mestre e Doutora em Ciência da Computação, professora da Faculdade de Educação e do Programa de Pós-Graduação da UFRGS, além de Coordenadora do Núcleo de Tecnologia Digital Aplicada à Educação NUTED da Faculdade de Educação, vinculado ao Centro Interdisiciplinar de Novas Tecnologias na Educação (CINTED).

A obra aqui referida foi lançada em 2013 e está organizada em 14 capítulos que versam sobre competências na educação, especialmente na Educação a Distância - EAD, apresentando as competências necessárias a professores, alunos, tutores e gestores para atuar no contexto da EAD, em diferentes instâncias.

No primeiro capítulo, as autoras tratam de definir o termo competências e seus elementos constituintes, buscando esclarecer alguns conceitos importantes para a compreensão dos capítulos seguintes. O termo competência, no contexto deste livro, compreende um conjunto de elementos composto por Conhecimentos, Habilidades e Atitudes (CHA). Estes três elementos, formadores da competência, necessitam ser mobilizados para atender a determinada necessidade que emerge em situações específicas. São apresentados os recursos de suportes, mobilização e evolução com base na teoria de Piaget, onde o ser humano é caracterizado em dois sujeitos: o epistêmico e o psicológico.

O segundo capítulo apresenta a definição e características da educação a distância e a significado do sujeito na EAD subsidiado novamente em Piaget para definir a relação entre o meio, objeto e sujeito psicológico, que é caracterizado pelo que é pessoal e exclusivo, como os

\footnotetext{
a Mestranda em Educação pela Pontifícia Universidade Católica do Rio Grande do Sul (PUCRS). E-mail: < gisellemassaro@ gmail.com>.
} 
sentimentos, emoções, forma de pensamento e ações. O capítulo é finalizado com a apresentação dos quatro domínios necessários a EAD: o tecnológico, o cognitivo, o sociocultural e o de gestão.

Os quatro capítulos seguintes tratam cada um dos domínios citados anteriormente. O capítulo 3 trata o domínio tecnológico que conforme as autoras, é compreendido como um conjuntos de competências relacionadas ao uso dos recursos tecnológicos seja na modalidade presencial, semipresencial ou totalmente a distância. As competências elencadas neste domínio, resumidamente, são: o letramento digital, a cooperação, a autonomia, a organização a comunicação e a presença social. Cada uma destas competências é esmiuçada neste capítulo pelas autoras, que, ao final, destacam que outras competências, providas dos aspectos socioculturais, nos quais os sujeitos da EAD estão inseridos, podem ser consideradas no domínio tecnológico.

O capítulo 4 tem como objetivo discutir as possíveis relações entre a noção de competência em educação e o domínio cognitivo na perspectiva de Piaget. Neste capítulo as autoras Moresco e Behar, realizam uma análise do domínio cognitivo piagetiano, esclarecendo como ocorre a construção do conhecimento. Ao final do capítulo as autoras concluem ressaltando o papel determinante da ação na noção de competência, e ainda, que o profissional competente sabe como mobilizar recursos necessários ao desenvolvimento de determinada situação. Além de saber o que fazer, sabe como e quando deve fazer.

O domínio sociocultural, abordado no quinto capítulo, perpassa as relações intra e interpessoais. O capítulo aborda o trabalho em equipe no contexto do trabalho, no campo da educação e no campo da computação. Apresentamse também as ferramentas colaborativas digitais que podem ser utilizadas coletivamente tanto no trabalho como na educação.

O capítulo 6 apresenta o domínio de gestão em EAD, ressaltando o papel do coordenador de curso de ensino superior nessa modalidade de ensino, caracterizando o domínio de gestão sobre a ótica das competências. As competências básicas do coordenador de curso EAD são apresentadas e mapeadas como conhecimentos, habilidades e atitudes que podem ser empregadas independentes da área de conhecimento do curso.

Nos capítulos seguintes foram elencados oito capítulos que se referem às competências em diferentes áreas de conhecimento da educação a distância. O capítulo 7 versa sobre a competência de cada um dos atores da educação a distância, os quais seriam o professor, o aluno e o tutor, apresentando as características e especificidades de cada um dos sujeitos.

As competências docentes para a prática pedagógica na educação a distância é a temática do capítulo 8 . Primeiramente é feita uma análise da didática e suas contribuições para a educação a distância. Na sequência, apresenta-se um levantamento acerca dos saberes necessários a docência, a partir de autores que contribuem para esta reflexão, tais como Tardif, Cunha e Perrenoud. 
No nono capítulo as autoras discorrem sobre os conceitos e características do metaverso para a educação e elencam as competências docentes necessárias para seu o uso na educação a distância. Metaversos permitem a criação de mundos digitais virtuais em 3D e caracterizam-se por ambientes dinâmicos, que são modificados à medida que os usuário interagem com ele. A interação ocorre entre os sujeitos e entre o sujeito com os objetos e com os espaços do próprio ambiente. As autoras destacam que a interação e a interatividade acontecem em tempo real, pois exigem a presença digital virtual para exercê-la. No metaverso o sujeito é representado por um avatar criado e caracterizado por ele. As autoras elencaram 8 competências docentes necessárias para o uso do metaverso na EAD, as quais seriam: planejamento, mediação pedagógica, didática, relação interpessoal, autonomia, fluência digital, comunicação e presença virtual.

No capítulo 10, são introduzidos estudos sobre letramento digital, tendo em vista a necessidade de instrumentalização de professores para o uso efetivo das Tecnologias da Informação e Comunicação - TICs, amplamente utilizadas pelos seus alunos nativos digitais. Conforme Ribeiro e Behar, os professores devem tornar-se guias para seus alunos para que estes façam uso da tecnologia de forma significativa no contexto escolar. Embora os estudos sobre letramento façam parte do cotidiano do professor que utilizam a tecnologia em momentos de ensino e de aprendizagem, as competências para uso efetivo das TICs ainda são desconhecidas por muitos deles. De acordo com as autoras, a exploração dos conceitos de letramento por meio das competências possibilita a compreensão dos conhecimentos, habilidades e atitudes necessárias para uma participação ativa e competente neste contexto educacional impactado pelas tecnologias, e assim aperfeiçoar ou iniciar a utilização das tecnologias, identificando quais conhecimentos, habilidades e atitudes precisam ser desenvolvidas ou modificadas.

No capítulo 11, discutem-se as competências necessárias para os alunos idosos na EAD. São elencadas 8 competências: fluência digital, resiliência virtual, literácia virtual, comunicação, interação, cooperação, organização e autonomia. As autoras destacam que apesar de a maioria das competências serem as mesmas necessárias a alunos virtuais de qualquer idade, o que diferencia é a intensidade com que os idosos usufruem dos elementos envolvidos para desenvolverem as competências em determinadas situações. As autoras concluem dizendo que apesar de a participação do idoso na EAD ser recente, este público apresenta-se com grande potencial para serem alunos virtuais, e destacam a importância das organizações governamentais investirem em cursos online para idosos. Destacam ainda, que este público, em sua maioria, retorna aos estudos não para qualificar-se para o mercado de trabalho, mas sim para sua autovalorização e afirmação como cidadãos produtivos e ativos na sociedade contemporânea.

O capítulo 12 apresenta os conceitos envolvidos na construção de materiais educacionais digitais - MED's baseados no design pedagógico, e elencam as principais competências necessárias à equipe desenvolvedora para a construção de MED’s. O conceito de Material Educacional Pedagógico apresentado neste livro é todo material voltado 
à aprendizagem e que utiliza um ou mais recursos digitais na sua elaboração. São descritos como exemplo as páginas web como blog, wiki, agregadores de notíciais web, e ainda os softwares educacionais e os objetos de aprendizagem. Com relação às equipes de desenvolvimento, Torrezzan e Behar afirmam que, a equipe responsável pela criação de MED's deve ter uma composição interdisciplinar formada por profissionais de diferentes áreas, como design, pedagogo e programador. Nas seções seguintes deste capítulo, as autoras abordam os principais temas relacionados à construção de MED’s: educação por competências, design pedagógico e experiência estética.

As competências necessárias para o uso das tecnologias de informação e comunicação na formação de professores que atuam na presencialidade ou a distância no contexto tecnológico-musical é a temática abordada no capítulo 13. Neste capítulo, as autoras conversam com autores como Peretz, Hargreaves e Stefani onde são apresentados ao leitor fatores no desenvolvimento de competências para a música. As autoras destacam as possibilidades da Web 2.0 que permitem tanto o compartilhamento de informações entre alunos, tutores e professores, como a possibilidade de autoria de suas produções, devido à existência de ferramentas que permitem criar suas próprias mídias digitais, integrando sons, vídeos, imagens e textos, tanto para músicos especialistas como para pessoas leigas em música. Existem muitos softwares que podem ser utilizados como recursos na aprendizagem, porém as autoras destacam que a maioria destes softwares são desenvolvidos para uso comercial e não educacional, e são em língua inglesa, o que restringiria seu uso a uma pequena parcela da população. Apesar disso, estes recursos servem como apoio didático e pedagógico com conteúdos consistentes, e a sua utilização apoiada por um Ambiente Virtual de Aprendizagem possibilita o desenvolvimento de conhecimentos, habilidade e atitudes necessárias para o contexto tecnológicomusical na EAD. As autoras concluem expondo que acreditam que uma formação adequada para o contexto em questão, deve ser oferecida em cursos de formação inicial e continuada de professores e que nestes cursos deveriam ser incluídas disciplinas que tratem a música associada às tecnologias digitais.

Por fim, no capítulo 14, que encerra a obra em questão, apresenta-se um panorama da fluência digital na sociedade da informação, em que Tarouco faz um contraponto entre alfabetização digital e fluência digital. Neste contexto, alfabetização digital pressupõe apenas habilidades básicas para a utilização das tecnologias digitais como simples consumidores da informação. Porém, conforme a autora, educar em uma sociedade do conhecimento pressupõe, além destes conhecimentos básicos, desenvolver competências que permitam as pessoas atuação efetiva na produção de bens e serviços, operar com fluência sobre esses meios e ferramentas, não sendo apenas consumidores, mas também criadores de informação. O contexto em que vivemos é permeado em abundância de informação as tecnologias digitais que se atualizam muito rapidamente. A educação necessita atualizar não apenas o contexto e os recursos tecnológicos, como também a demanda por professores com fluência digital. Conforme dados apresentados do CETIC.br, uma grande quantidade de professores não recebeu formação para o uso das tecnologias da informação e comunicação, 
pois isto não constavam no programa do curso, quando foram realizados. A autora finaliza o capítulo expondo que a transformação da educação no país, para melhor preparar o cidadão do século XXI, demanda esforço para a formação continuada de professores, a fim de complementar a formação recebida pelos docentes que concluíram seus cursos no século XX.

A proposta apresentada pelo livro é cumprida em seus 14 capítulos que abordam a educação, as competências e a educação a distância por diferentes perspectivas e direcionadas a diferentes interesses, sendo a sua leitura indicada para profissionais que atuem na EAD ou pessoas que tenham interesse em se inteirar sobre o tema. As autoras apresentam o conteúdo de forma clara, utilizando-se de mapas e esquemas que auxiliam na compreensão e sintetização das ideias apresentadas nos capítulos. Sendo assim, recomendamos este livro, que é de agradável leitura e apresenta conteúdo consistente e atual.

\section{Endereço para correspondência:}

Geselle Massaro

Rua João Goulart, 96

96745-000 Charqueadas, RS, Brasil

E-mail: <gisellemassaro@gmail.com>

Recebido em: jun./2014

Aceito em: ago./2014 